O experimento virtual da dupla fenda ao nível do ensino médio (Parte II): uma análise quântica do comportamento corpuscular e ondulatório da $\operatorname{luz}^{+*}$

\author{
Danilo Cardoso Ferreira ${ }^{1}$ \\ Instituto Federal do Paraná - IFPR \\ Jacarezinho - PR \\ Moacir Pereira de Souza Filho ${ }^{1}$ \\ Universidade Estadual Paulista - UNESP \\ Presidente Prudente - SP
}

\title{
Resumo
}

Nosso trabalho analisa o experimento virtual da dupla fenda e está dividido em duas partes: a Parte I (publicada) que tratou da análise clássica do comportamento (corpuscular e ondulatório) e a Parte II (o presente artigo) que aborda o comportamento quântico da luz (fótons). Nosso processo metodológico se dividiu em 3 (três) etapas: (i) analisamos, primeiramente, com o auxílio de experimentos virtuais, o comportamento de um feixe de luz que atravessou uma parede com duas fendas. Neste caso, percebe-se que a luz sofre interferência. (ii) Em seguida, utilizamos o mesmo experimento, mas agora com fótons individuais. Os fótons se comportam como ondas e sofrem interferência, como antes. (iii) Finalmente, para descobrir o que estava acontecendo, colocamos um detector próximo às fendas. Nesta situação, estranhamente, os fótons se comportaram como partículas (corpúsculos). Com o objetivo de explicar estes resultados, utilizamos a notação de brackets proposta por Paul Dirac (1902-1984) que nos permite representar os vetores de estado, os quais nos propiciam mostrar, matematicamente, o que ocorre no experimento da dupla fenda com objetos quânticos. Devido à complexidade matemática (para o ensino médio) intrínseca à notação de Dirac fizemos uma espécie de "tradução" deste recurso matemático para este nível de

\footnotetext{
+ The virtual double-slit experiment to the High School level (Part II): a quantum analysis of behavior corpuscular and wave aspect of the light

* Recebido: junho de 2018. Aceito: fevereiro de 2019.

${ }^{1}$ E-mails: danilo.ferreira@ifpr.edu.br; moacir-pereira.souza-filho@unesp.br
} 
ensino. Acreditamos que este artifício poderá ser útil para a compreensão de outros conceitos da mecânica quântica, tais como spin 1/2 e sistemas de dois níveis.

Palavras-chave: Mecânica Quântica; Experimento da Dupla Fenda; Ensino de Física.

\begin{abstract}
This work analyzes the virtual double slit experiment and it has been divided into two parts: Part I, which dealt with the classical behavior analysis (corpuscular and wave) and Part II (this article) addresses the quantum behavior of light (photons). The methodology process has been divided into three (3) steps: (i) First, we analyze based on the use of virtual experiments, the behavior of a beam of light across a wall with two slits. In this case, it is light shows interference. (ii) Then, we use the same experiment, but in this situation with individual photons. The photons behave like waves and show interference, such as before. (iii) Finally, to find out what was happening, put a detector near the cracks. In this situation, strangely, the photons behave like particles (corpuscles). In order to explain these results, we use the notation of brackets proposed by Paul Dirac (1902-1984) that allows us to represent the state vectors, which allow us to show, mathematically, what happens in the double slit experiment with quantum objects. Due to the mathematical complexity (for high school) intrinsic to the notation of Dirac we proposed a sort of "translation" of this mathematical resource for this level. We believe that this device could be useful for understanding other concepts of quantum mechanics, such as spin 1/2 and two-tier systems'.
\end{abstract}

Keywords: Quantum Mechanics; the Double-Slit Experiment; Physics Teaching. 


\section{Introdução ${ }^{2}$}

Este trabalho foi dividido em duas partes: na parte I, abordamos o experimento da dupla fenda analisando, classicamente, o comportamento de corpúsculos e ondas provenientes de uma fonte, ao atravessarem as fendas e incidirem num anteparo. No presente artigo, parte II, vamos abordar e analisar, quanticamente, como a luz (constituídas por fótons) se comporta, no mesmo experimento. Para isso, utilizaremos dois experimentos virtuais analisando as diversas possibilidades e, ao final, faremos uma análise deste comportamento por meio de uma matemática elementar proposta por Feynman (FEYNMAN et al., 2008). No entanto, inicialmente, faremos uma contextualização histórica sobre a natureza da luz.

O embate entre as concepções corpuscular e ondulatória da luz, data dos povos antigos e não vamos entrar em detalhes, pois foge ao escopo deste artigo. Nosso objetivo principal, simplesmente, apresentar ao leitor um panorama sobre as visões corpuscular, ondulatória e dual da luz, enfatizando esta última, que será a base deste artigo.

Analisando os trabalhos e experimentos de Isaac Newton (1643-1727) parece evidente que ele defendia o modelo corpuscular ou balístico da luz ${ }^{3}$, diferentemente de Descartes, Hooke e Huygens e de Young, Fresnel e Maxwell. Esta crença, segundo Assis (2002) está pautada basicamente em três linhas de raciocínio: (i) o atomismo na época e sua concepção sobre o éter (densidade menor e elasticidade maior que o ar); (ii) a propagação retilínea do raio de luz, diferentemente de um fluído; como dito por Newton: “[...] nunca se soube de a luz seguir passagens curvas, nem de curvar para a sombra [...]" (iii) a invariância das propriedades da luz, em especial a permanência da cor "[...] os corpúsculos emitidos pelas substâncias que brilham, e que constituiriam os raios de luz [...]" conservam imutáveis suas propriedades, ao atravessarem meios distintos (NEWTON apud. ASSIS, 2002, p. 23-7).

A teoria ondulatória foi, primeiramente, sistematizada por Christian Huygens (1629$1695)^{4}$, que propôs conceitos de pulsos de luz propagados pelo éter, mas parece que na época, devido ao prestígio de Newton, a teoria corpuscular (série de corpos pequenos emitidos pelos corpos luminosos) acabou prevalecendo. Embora a historiografia indique que não houve um

\footnotetext{
2 Esta introdução representa um breve recorte histórico para elucidação do tema central deste artigo. Sugerimos aos leitores interessados num aprofundamento histórico/conceitual/teórico que consultem as referências citadas no final deste artigo, ou demais trabalhos igualmente confiáveis. Há algumas obras de cientistas famosos traduzidas para o português, tais como: Bohr (1996, p. 41-83) que narra seu debate com Einstein; Feynman (2012, p. 133-153) que analisa o experimento da dupla fenda; Heisenberg (1996, p. 87-99) que narra o debate entre Bohr e Schrödinger; Planck (2012, p. 41-57) que trata do rompimento da causalidade e o determinismo na Física; Planck (2012, p. 189-215) que trata da natureza das leis físicas.
}

${ }^{3}$ Segundo Moura (2018, p. 116), embora Newton adotasse a concepção corpuscular, nunca defendeu abertamente em seus escritos: "não há ao longo do texto uma defesa explicita aos corpúsculos de luz". Ao questionar na questão 26 do seu livro Óptica se os raios seriam corpos minúsculos emitidos por substâncias que brilham (afirmação negativa na forma de questão), deixa implícita uma resposta afirmativa.

${ }^{4}$ É importante destacar que o modelo ondulatório de Huygens é distinto daquele que concebemos atualmente, pois "estava baseado numa perturbação mecânica por meio de forças de contato entre corpúsculos" (SILVA, 2007, p. 149). Ele não apresentou uma teoria ondulatória no sentido moderno: por exemplo, não há conceitos como periodicidade, frequência, etc. (MOURA, 2016, p. 114). 
embate generalizado e acirrado entre esses dois cientistas, as ideias de Newton e, principalmente, sua autoridade, aparentemente, favoreceram a aceitação da sua teoria. (MOURA, 2016).

Somente em 1801, Thomas Young (1773-1829) demonstrou a interferência da luz por meio do experimento da dupla fenda. Nas palavras de Silva (2007, p. 155) a "luz emergente dispersa-se por difração e incide em dois novos orifícios, ocorrendo uma nova difração. A superposição entre as ondas provenientes destes orifícios gera um padrão de interferência em um anteparo". Étiene Malus (1775-1812) tentou contestar o trabalho de Young, ao mostrar por meio de um experimento com um cristal de dupla refração, que a imagem do disco solar refletida nas janelas do Palácio de Luxemburgo era única, ao invés de duas imagens. Porém, o trabalho de Augustin Fresnel (1788-1827) demonstrou, matematicamente, que se fosse admitido a teoria ondulatória "deveria aparecer um ponto brilhante no centro da sombra de um obstáculo circular opaco, justamente no ponto mais protegido", posteriormente, isso foi confirmado pela experiência. Além disso, Jean León Foucault (1819-1868) determinou a velocidade da luz em diferentes meios, fortalecendo ainda mais a teoria ondulatória (Ibid.).

Na segunda metade do século XIX, James C. Maxwell (1831-1879) sintetizou as equações do eletromagnetismo, demostrando que campos elétricos e magnéticos satisfazem as equações de onda e se propagam perpendicularmente entre si com a velocidade da luz. Mais tarde, Heinrich Hertz (1857-1894) realizou experimentos que comprovaram as ondas de rádio. Assim, nesta época ficou bem estabelecido que a luz era uma onda eletromagnética que se propagava com um valor finito e constante.

A grande revolução sobre a concepção da luz ocorreu com o surgimento da Mecânica Quântica, no início do século XX. O cientista Albert Einstein (1879-1955) publicou um trabalho denominado "sobre um ponto de vista heurístico a respeito da produção e da transformação da luz” (EINSTEIN, 1905 apud. STACHEL, 2005). Neste trabalho, ele reconhece a validade da teoria ondulatória dizendo:

De acordo com a teoria de Maxwell, a energia é considerada uma função espacial contínua para todos os fenômenos eletromagnéticos e, portanto, também para luz [...] a teoria ondulatória da luz, que opera com funções espaciais contínuas, provouse sobremaneira adequada na descrição de fenômenos puramente óticos, e provavelmente, nunca será substituída por outra [...] e é bastante concebível, a despeito da teoria da difração, reflexão, refração, dispersão, etc.

No entanto, neste artigo Einstein (1905) defende a noção "granular" da luz, "pacotes de energia", ou ainda, "quanta de luz", que mais tarde veio a ser chamada de "fótons":

[...] a luz é distribuída de forma descontínua no espaço. De acordo com a hipótese aqui considerada, na propagação de um raio de luz emitido por uma fonte puntiforme, a energia não é continuamente distribuída sobre volumes cada vez maiores de espaço, mas consiste em um número finito de quanta de energia, localizados em 
pontos do espaço que se movem sem se dividir, e que podem ser absorvidos ou gerados somente como unidades integrais.

De acordo com Rosa (2004, p. 165) é comum pensar que a proposta onda-corpúsculo foi, inicialmente, proposta por Einstein, porém (como mostra a citação anterior e de acordo com referido o autor), o que cientista alemão defendeu foi a presença de um corpúsculo no interior da radiação (hipótese do quantum de luz) diferente da concepção dualística da luz pensada por Louis de Broglie (1892-1987). Segundo Rosa (2004, p. 3) “a contribuição de De Broglie para o desenvolvimento da teoria do quantum pode ser compreendida como uma síntese que combina os aspectos de ondas e partículas, tanto para luz, quanto para partículas, como o elétron". Assim, por analogia, se a onda luminosa tem uma partícula associada (quantum de luz), então, um determinado pedaço de matéria [...] (corpúsculo) também deveria apresentar uma onda [fictícia] associada" à ela (ROSA, 2004, p. 168). Nas palavras de De Broglie: "desenvolvi novas ideias que [...] unificará a física das radiações, que hoje em dia está cindida de forma tão estranha em dois domínios onde reinam duas concepções opostas: a concepção corpuscular e das ondas" (Ibid., p. 164).

A tese elaborada por De Broglie, ao buscar a unificação dos conceitos de onda e partícula, tornou-se compatível com a hipótese mutuamente excludente do princípio da complementariedade proposta por Niels Bohr (1885-1962) a qual sugeria que, "sob certas condições físicas a radiação (luz) teria o comportamento de onda ou partícula; o elétron (matéria), conforme as condições, teria também um comportamento de partícula ou de onda" (Ibid., p. 168).

Esta contextualização histórica, mostra de maneira sintética, que a concepção sobre a natureza da luz foi polêmica e dinâmica no decorrer da história. Tivemos oportunidade, na parte I deste trabalho de mostrar o experimento clássico da dupla fenda para corpúsculos e ondas. Neste artigo, abordaremos quanticamente a visão dual da luz.

\section{Um panorama geral sobre o artigo}

O processo metodológico adotado neste trabalho está dividido, basicamente, em 3 (três etapas) que foram trilhadas por nós, e teve por objetivo tornar nossas considerações mais didáticas.

Na etapa, (i) utilizamos o experimento virtual Interferência de Ondas ${ }^{5}$, a fim de observar o comportamento de um feixe luz quando atravessa uma parede constituída por duas pequenas fendas ou orifícios. Supondo que a luz é constituída de pequenos corpúsculos (denominados fótons), ao incidirmos um feixe de luz num anteparo, tendo neste trajeto uma parede com duas fendas, espera-se observar no anteparo, duas regiões com maior incidência de fótons, uma vez que, somente os fótons que atravessam as fendas, chegariam ao anteparo. Chamaremos esta assertiva de afirmação $A$.

5 Disponível em: <https://phet.colorado.edu/pt_BR/simulation/legacy/wave-interference>. Acesso em: 11 abr. 2016. 
$\mathrm{Na}$ etapa (ii), mudamos a distância entre as fendas, e notamos a presença de três ou mais regiões com grande incidência de luz, ou seja, neste caso, os resultados mostraram que a luz sofre interferência. Esse resultado é tipicamente característico de fenômenos ondulatórios e foi obtido por nós com ondas no experimento da dupla fenda. Chamaremos esta assertiva de afirmação $B$.

Comparando as afirmações $A$ e $B$ nos deparamos com uma contradição lógica. Pessoa $\operatorname{Jr}(2003)$ sintetiza esta situação no seguinte trecho:

Dizer simplesmente que "uma coisa (sem partes) é (ao mesmo tempo) partícula e onda" é uma contradição lógica. Pois isso implicaria que essa coisa é indivisivel e divisivel (contínua), que ela segue uma trajetória e não segue (é espalhada). Não podemos admitir uma contradição nos fundamentos de uma teoria física (apesar de este ponto ser passível de discussão).

Para explicar o que acontece com a luz no experimento da dupla fenda, utilizamos o experimento virtual Interferência Quântica ${ }^{6}$, que constitui a etapa (iii) do processo investigativo (OSTERMANN, RICCI; 2005). Este simulador nos possibilita inserir detectores em qualquer região do aparato experimental virtual da dupla fenda. Desta forma, introduzimos detectores nas fendas para "aferir" o que acontece com os fótons no momento de sua "travessia" pela fenda. O resultado com os detectores muda. Nesta situação os fótons se comportam como partículas, quando observados com os detectores.

A partir dos resultados dessas três etapas, podemos discutir como um detector pode interferir na medida por qual fenda o fóton atravessa, ou seja, como o detector interage com o fóton provocando uma mudança no resultado da atividade experimental. Podemos, neste momento, nos indagar sobre a limitação no processo de medida da física quântica.

O processo experimental utilizado até o momento não nos permite explicar de forma clara os resultados do experimento da dupla fenda. Para contornar o problema e nos apoiar em um referencial consistente, recorremos ao formalismo matemático da mecânica quântica, que prevê com grande precisão, os resultados no aparato do experimento da dupla fenda. Escolhemos a notação de Dirac, brackets, para matematicamente explicar, utilizando vetores de estado, cada resultado do experimento da dupla fenda com objetos quânticos.

Devido à complexidade matemática (para o ensino médio) de trabalhar com vetores de estados, realizamos uma revisão bibliográfica do livro Lições de Física de Feynman: mecânica quântica (FEYNMAN et al., 2008). No referido trabalho, Feynman e colaboradores constroem regras para utilizar o formalismo de Dirac no experimento da dupla fenda. Utilizando estas regras, podemos explicar, matematicamente, os resultados do experimento da dupla fenda com objetos quânticos. Desta forma, é possível discutir as facilidades de se utilizar a "tradução" da notação de brackets de Dirac para o ensino médio, ou em disciplinas de

\footnotetext{
${ }^{6}$ Disponível em: <https://phet.colorado.edu/pt_BR/simulation/legacy/quantum-wave-interference>. Acesso em: 11 abr. 2016.
} 
mecânica quântica para graduação e pós-graduação, tais como, estrutura da matéria ou física quântica.

Quando tentamos explicar o estranho comportamento do fóton no experimento da dupla fenda, uma vez que se atribuirmos a ele a condição de partícula, ficaremos impossibilitados de explicar o fato do fóton sofrer o fenômeno da interferência e; quando tentamos observar por qual fenda o objeto quântico atravessou, os mesmos não se interferem e comportam-se como partícula. Finalizaremos o artigo apresentando duas escolas de pensamento: dualista realista objetiva (que sugere que objetos quânticos apresentam simultaneamente características corpusculares e ondulatórias) e a interpretação de Copenhagen (cientistas adeptos da exclusão mútua, ou seja, do princípio da complementariedade de Bohr e também do Princípio da Incerteza de Heisenberg).

\title{
III. Comportamento Quântico
}

O experimental da dupla fenda com objetos quânticos (JÖNSSON 1974; ZEILINGER et al., 1988; CARNAL, MLYNEK 1991; SHIMIZU et al., 1992), é descrito por Feynman (FEYNMAN et al., 2008), da seguinte forma:

\begin{abstract}
Um canhão de elétrons, que consiste em um filamento aquecido de tungstênio, é enclausurado em uma caixa de metal com um orifício. Se o fio tiver uma voltagem negativa em relação a caixa, os elétrons emitidos pelo filamento serão acelerados na direção da parede e alguns passarão pelo orifício. Todos os elétrons emitidos pelo filamento terão (essencialmente) a mesma energia. Na frente do canhão mais uma vez temos uma parede (fina de metal) com dois orifícios. Além da parede, esta outra placa que servirá como anteparo. Na frente do anteparo colocamos um detector móvel. O detector pode ser um contador Geiger ou, talvez, até melhor, uma multiplicadora de elétrons, que será conectada a um alto-falante [...] A primeira coisa que notamos com a experiência é que ouvimos um clique sempre que um elétron atinge o detector (o alto-falante). E todos os cliques são iguais. Não existe "meio clique".
\end{abstract}

Para mostrar o experimento descrito por Feynman utilizamos, inicialmente, o simulador Interferência de Ondas que permite trabalhar com a luz e um aparato experimental com duas fendas. Feynman desenvolveu sua explanação utilizando elétrons. Como os resultados são semelhantes e, no primeiro experimento virtual não temos a opção de experimento de fenda dupla com elétrons, necessitamos desenvolver o trabalho com luz. Com este experimento virtual podemos mostrar o que denominamos comportamento quântico dos fótons (GALVEZ et al., 2017), isto é, a dualidade onda-partícula. 


\section{III.1 Interferência de Ondas (fenda simples)}

A Fig. 1a mostra a imagem do simulador, após ser iniciado, com os parâmetros que selecionamos e que explicaremos, a seguir. Utilizamos no experimento uma "lâmpada" para analisar o comportamento da luz. Após a "lâmpada" ser ligada inserimos entre a fonte e o anteparo uma "barreira" com uma fenda ou orifício. Para analisar o que ocorre com os fótons que chegam no final do percurso, selecionamos a função "mostrar tela" que apresenta os pontos com maior incidência de luz. Apenas após escolhida esta função, aparece uma nova função denominada "gráfico de intensidade", que é selecionada e plota o gráfico da Fig. 1a.

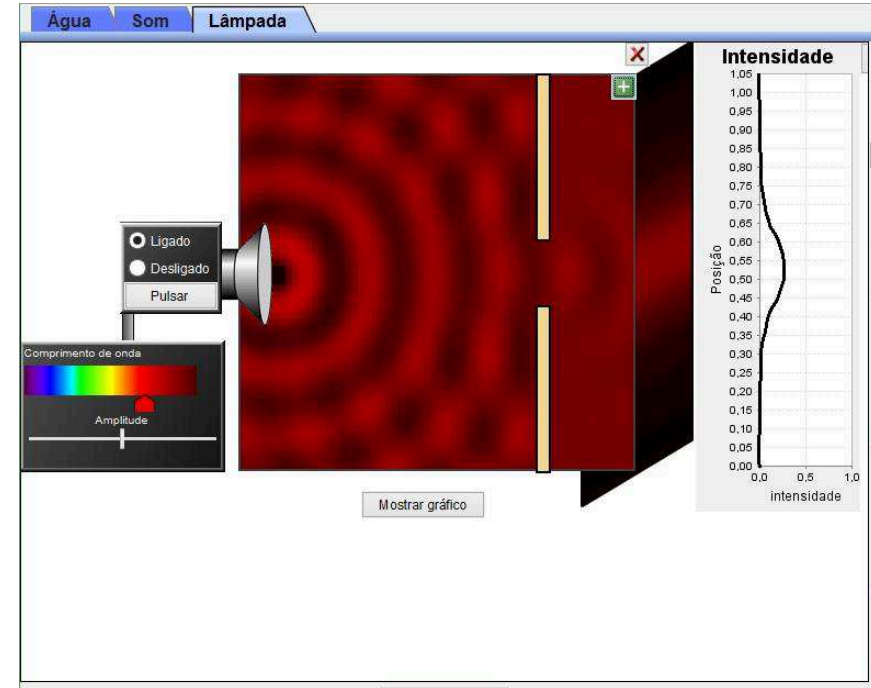

a)

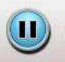

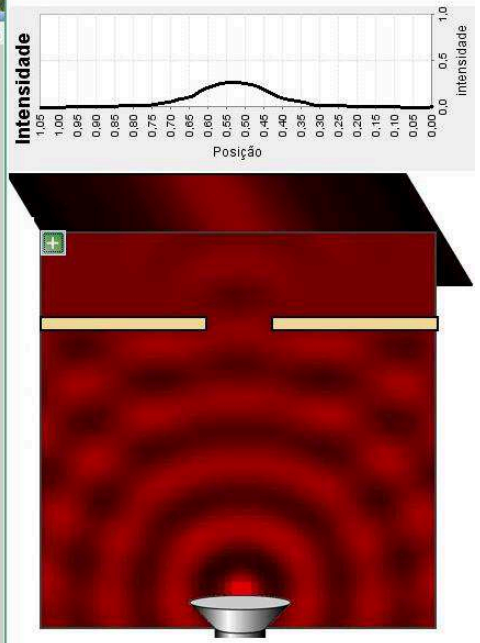

b)

Fig. 1 - Experimento virtual Interferência de Ondas com uma fenda.

Com o objetivo de tornar a explanação anterior mais clara, realizamos as seguintes modificações na Fig. 1a. O resultado pode ser visto na Fig. 1b.: i) realizamos uma rotação em $90^{\circ}$, no sentido anti-horário; ii) destacamos apenas as imagens da trajetória da luz, a tela e o gráfico de intensidade. O restante retiramos da figura para tornar mais clara a análise que faremos e; iii) rearranjamos os índices do gráfico de intensidade. Nas próximas figuras, com este experimento virtual, realizaremos as mesmas alterações.

Realizamos estas alterações por questões didáticas, pelos seguintes motivos. Primeiro: visualizar o gráfico de intensidade na horizontal, ou seja, como convencionalmente é feito, colabora com a facilidade na visualização do resultado7. Segundo: retiramos todas as informações laterais e inferiores, para restringir esta discussão ao resultado mostrado no gráfico de intensidade.

É importante destacar que o experimento proposto na Fig. 1 pode ocorrer difração da luz se a largura da fenda tiver a mesma ordem de grandeza do comprimento de onda da luz. $\mathrm{O}$

\footnotetext{
${ }^{7}$ Entendemos que o formato do gráfico na vertical não diminui a potencialidade do experimento. O gráfico surge de forma dinâmica. Caso sejam realizadas modificações nas fendas a intensidade muda paulatinamente.
} 
que chega ao anteparo é uma onda com o máximo de sua intensidade na reta que une o centro da fenda com o anteparo (FERREIRA, SOUZA FILHO; 2016).

\section{III.2 Interferência de Ondas (dupla fenda)}

Escolhemos a função "Duas fendas" e surge no simulador uma barreira com dois orifícios. Alteramos o tamanho de cada fenda, assim como a distância que as separam no cursor do experimento virtual, alterando o parâmetro "Largura da fenda" para o valor de $1050 \mathrm{~nm}$. Podemos observar, no gráfico de intensidade da Fig. 2, que temos duas regiões com maior intensidade de chegada de fótons. Este comportamento é típico de partículas e é denominado corpuscular (FERREIRA, SOUZA FILHO; 2016).
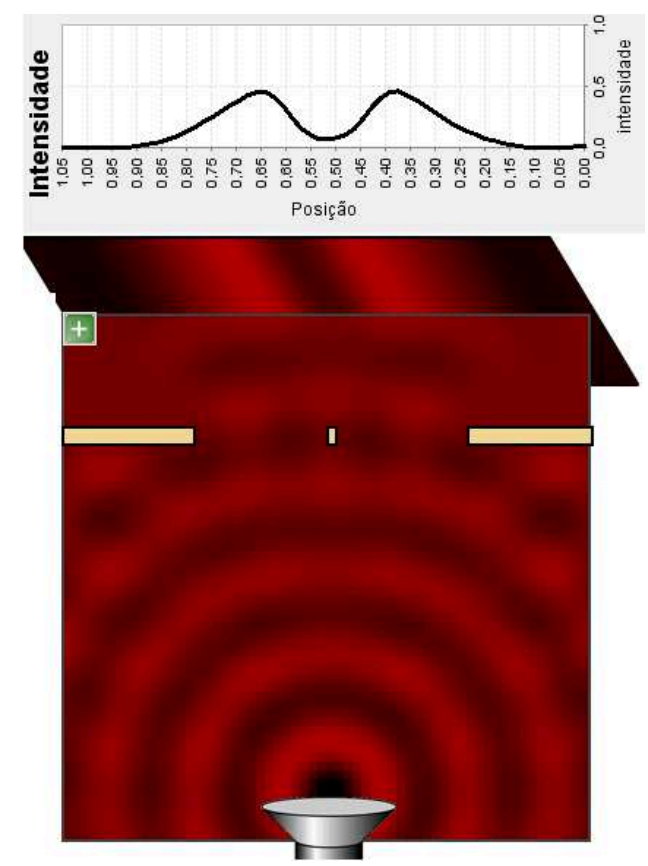

Fig. 2 - Experimento virtual Interferência de Ondas com duas fendas abertas.

No simulador Interferência de Ondas podemos utilizar a função "Adicionar espelho”. Surge um grande espelho no meio do experimento, na forma de um retângulo. Este espelho pode ter suas dimensões modificadas, ou seja, tanto aumentadas quanto diminuídas. Se diminuirmos o espelho de forma que fique, exatamente, nas dimensões da fenda, podemos cobrir a fenda. Desta forma, temos o experimento da dupla fenda, com uma das fendas fechadas. O resultado aparece na Fig. 3.

Na Fig. 3a cobrimos a fenda da direita. Desta forma, os fótons puderam passar apenas pela fenda do lado esquerdo, consequentemente, o gráfico de intensidade mostra o comportamento de partículas clássicas. O resultado é análogo para a fenda da esquerda fechada (Fig. 3b). Resumindo, a Fig. 3 mostra que quando uma das fendas é fechada o comportamento do fóton é de partícula. Caso as duas fendas estejam abertas, teremos o resultado mostrado na 
Fig. 2. Os resultados apresentados no experimento virtual possuem um aspecto visual muito próximo aos encontrados com experimentos reais (ZEILINGER et al., 1988). Esta é outra característica positiva deste simulador.
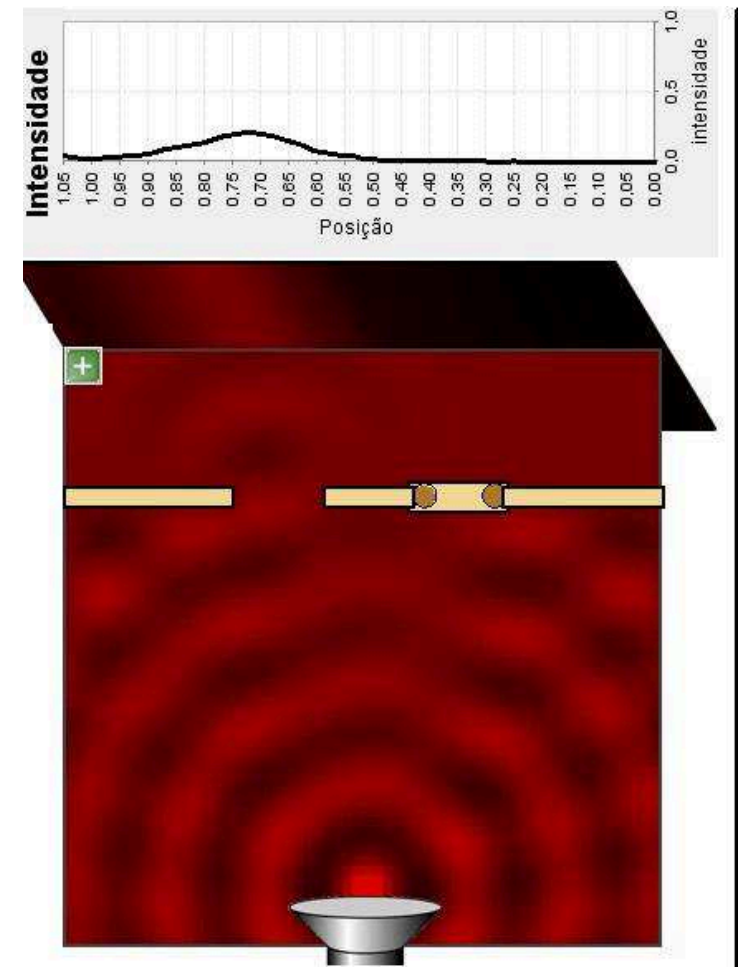
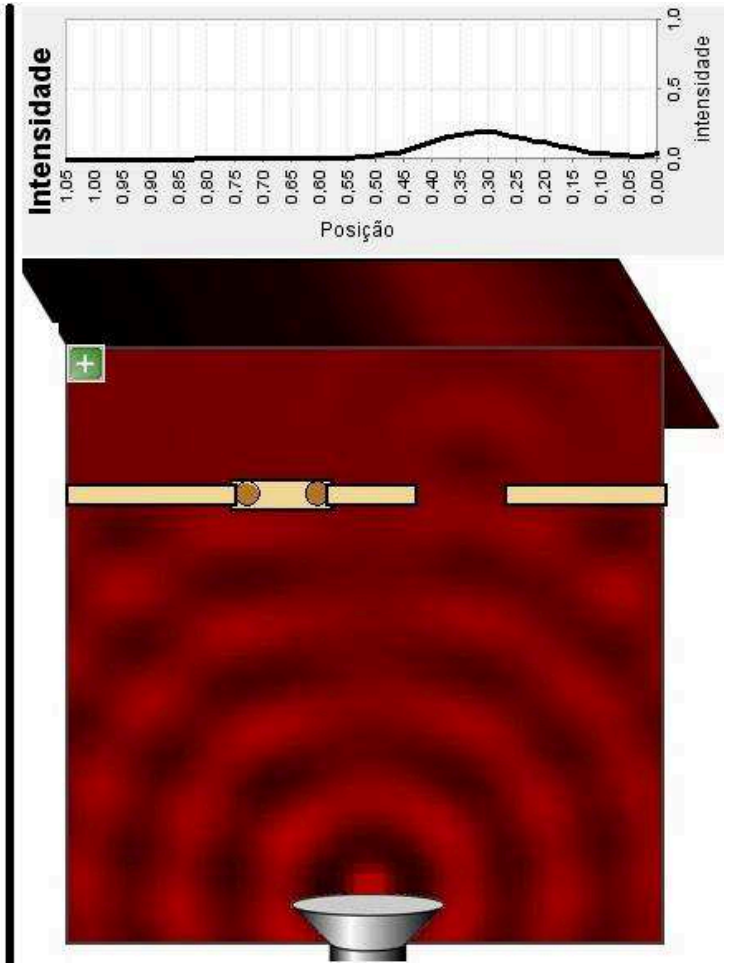

Fig. 3 - Experimento virtual Interferência de Ondas. a) a fenda da direita foi tampada. b) a fenda da esquerda foi tampada.

Podemos alterar o tamanho da fenda paulatinamente através da função "Largura da fenda". Também podemos utilizar a função "Separação das fendas" para tentar mudar o resultado no gráfico de intensidade. Conforme modificamos o tamanho da fenda, a luz na tela começa a sofrer interferência como mostrado na Fig. 4. Para produzir este resultado alteramos o parâmetro "Largura da fenda" para o valor de $525 \mathrm{~nm}$ (este resultado pode ser selecionado com precisão colocando cursor exatamente sobre a metade da régua de referência na opção "Largura da fenda").

Desta forma, podemos observar que o fóton, ora se comporta como partícula (Fig. 2 e 3), ora se comporta como onda (Fig. 4). Para conseguir mudar o comportamento da luz, isto é, de onda para partícula ou de partícula para onda, alteramos a largura da fenda. Neste momento explicamos porque dizemos que a luz possui um comportamento (onda ou partícula). Ela não é nem onda nem partícula, mas ora se comporta como um, ora se comporta como outro. Concluímos que o fóton possui comportamento quântico, pois se manifesta de forma dual dependo das características do aparto experimental. 


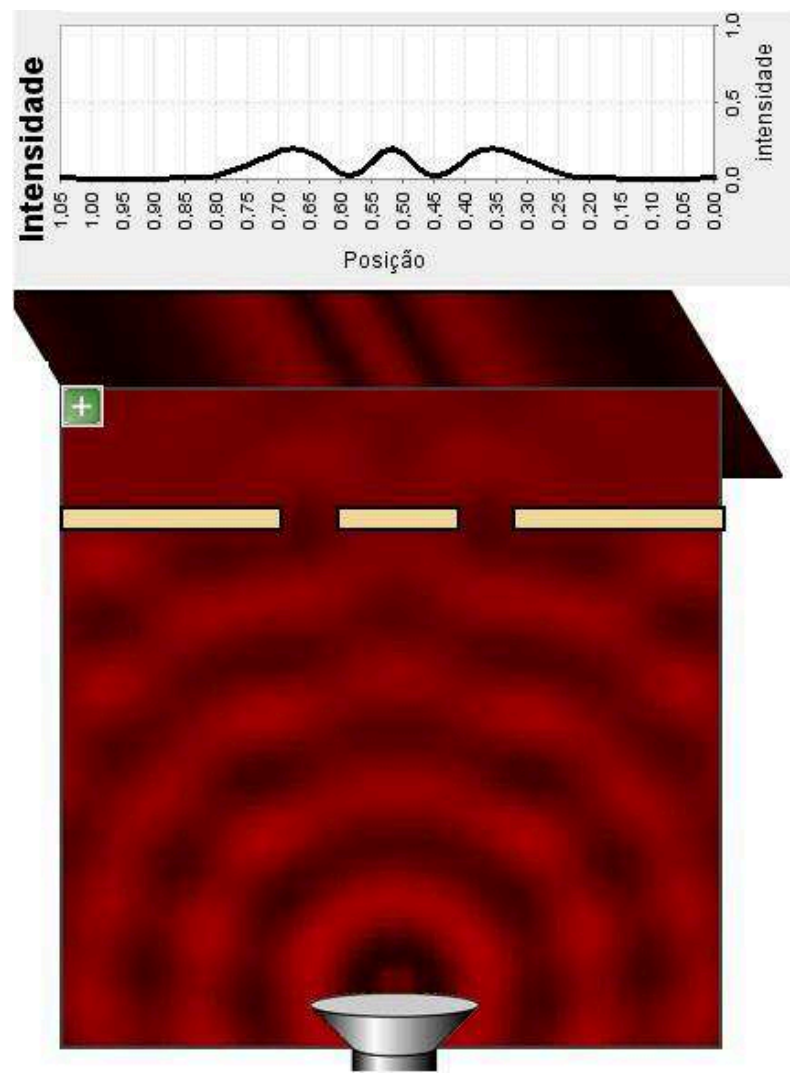

Fig. 4 - Experimento virtual Interferência de Ondas mostrando a interferência da luz de uma lâmpada que atravessa duas fendas.

Na primeira parte deste trabalho publicado neste periódico (FERREIRA; SOUZA FILHO; 2016), analisamos, matematicamente, os resultados encontrados nesta seção. Para os resultados com corpúsculos demonstrados na Fig. 5, com fótons se comportando como partícula, podemos concluir que a probabilidade de chegada de um fóton $P_{12}(x)$ no anteparo quando as duas fendas estão abertas é:

$$
P_{12}(x)=P_{1}(x)+P_{2}(x)
$$

onde $P_{1}(x)$ é a probabilidade de chegada através da fenda 1 e, $P_{2}(x)$ é a probabilidade de chegada através da fenda 2.

Quando a fenda 2 (fenda do lado direito na Fig. 2) está fechada (Fig. 3a), a intensidade é $I_{1}(x)$ e, quando a fenda 1 (fenda do lado esquerdo na Fig. 2) está fechada (Fig. 3b), a intensidade é $I_{2}(x)$. Os resultados com probabilidades mostrados na expressão 1 são para partículas, isto é, para o comportamento corpuscular do fóton e são comparados, devido a similaridade, com os resultados ondulatórios de intensidades onde $I_{1}(x)$ esta para $P_{1}(x)$ assim como $I_{2}(x)$ esta para $P_{2}(x)$.

Para os resultados encontrados na Fig. 4, quando o fóton sofre interferência, podemos comparar com os resultados mostrados na Parte I deste trabalho, no qual utilizamos um 
experimento virtual com "ondas de água". Para o tratamento matemático, trabalhos com a equação de onda escrita na sua forma complexa:

$$
y(x, t)=\operatorname{Re}\left[A e^{i(k x-\omega t+\delta)}\right]
$$

Após uma análise matemática das intensidades das ondas que chegam no anteparo quando ocorre o fenômeno de interferência, podemos concluir que:

$$
I_{12}(x)=I_{1}(x)+I_{2}(x)+2 \sqrt{I_{1}(x) I_{2}(x)} \cos \delta
$$

onde:

$$
\begin{aligned}
& I_{1}(x)=\left|h_{1}\right|^{2} \\
& I_{2}(x)=\left|h_{2}\right|^{2}
\end{aligned}
$$

Todos estes resultados podem ser conferidos com mais detalhes na Parte I deste trabalho, publicado neste periódico (FERREIRA, SOUZA FILHO; 2016). Fizemos este breve resumo, pois precisaremos destes resultados na seção VI para estudar a notação de brackets.

\section{Experimento virtual da dupla fenda com Detectores}

Se a dualidade onda-partícula mostrada na seção II é um fenômeno estranho, o mais surpreendente dos objetos quânticos não é o comportamento quântico, mas sim o que acontece quando tentamos observar por qual fenda o fóton atravessou. Para mostrarmos o que acontece nesta situação, utilizaremos outro experimento virtual denominado Interferência Quântica que está na Fig. 5.

Para obter o resultado apresentado na Fig. 5, podemos escolher entre trabalhar com a função "Alta intensidade" na Fig. 5a, ou, "Partícula única" na Fig. 5b. No lado direito do simulador (omitimos esta parte na imagem) podemos escolher a opção "dupla fenda" e o aparato experimental fica igual ao da Fig. 5. Surgem assim as opções (que podemos graduar): "Tamanho da fenda", "Separação das fendas" e "Posição vertical" das fendas. Além destas funções podemos optar por colocar um "Detector na fenda esquerda" (ou na fenda direita). Temos ainda outras opções como "anti-fendas"8 e "barreira de potencial". Podemos escolher qual objeto quântico desejamos utilizar, por exemplo: fótons, elétrons, nêutrons ou átomos de Hélio. Nossa opção foi fótons.

\footnotetext{
${ }^{8}$ A grafia atualmente aceita como correta é "antifendas". Entretanto, no simulador aparece "Anti-fendas", pois a tradução foi realizada antes da reforma ortográfica.
} 


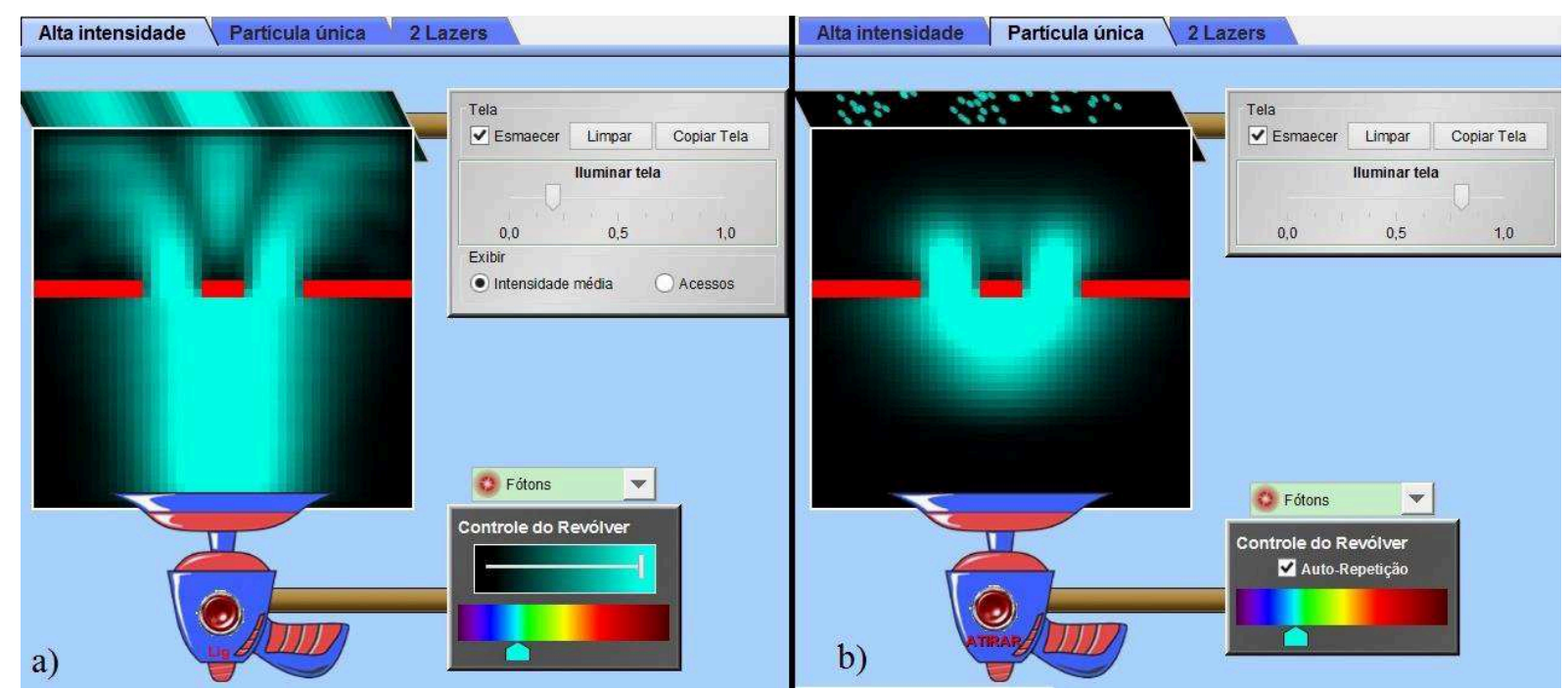

Fig. 5 - Experimento virtual Interferência Quântica. a) “Alta intensidade”. b) "Partícula única”.

Trabalhando com a opção "Alta intensidade" precisamos apenas "ligar" o laser no aparato experimental virtual da dupla fenda e podermos observar que a luz sofre interferência ${ }^{9}$, ou seja, os fótons se comportam como ondas. Observamos este resultado (Fig. 5a) devido às três faixas de luz espaçadas por regiões com menor incidência de fótons. Caso se formasse na tela duas faixas espaçadas por espaços vazios, ou uma única região contínua de luz, seria indícios de que os fótons se comportariam como partículas.

Também podemos observar a interferência da luz quando escolhemos trabalhar com fótons únicos, um a um, sendo lançados na parede com duas fendas. Para obter o resultado em menor tempo, escolhemos no simulador, as opções "Auto-repetição10" e "Rápido". Um a um, os fótons saem do "revólver" e chegam à tela. Mas, novamente, há a formação de três colunas com maior incidência de fótons, espaçadas por espaços quase vazios (Fig. 5b). Mais uma vez, o fóton que sai como partícula, se comporta como onda, pois sofre interferência.

Este experimento virtual é completo no sentido de que as ferramentas nele contidas explicam o comportamento quântico de partículas subatômicas. Entretanto, o experimento virtual Interferência de Ondas da seção anterior, possui a função que mostra o gráfico de intensidade. Didaticamente é mais simples entender o experimento da dupla fenda analisando as mudanças nos gráficos de interferência, pois a literatura cientifica (JÖNSSON 1974; ZEILINGER et al., 1988; CARNAL, MLYNEK 1991; SHIMIZU et al., 1992) apresentam resultados desta forma. Outra limitação neste simulador é o da tela apresentar apenas três regiões com acúmulo de partículas. Para aumentar a qualidade do experimento virtual o resultado

\footnotetext{
9 O trabalho de Claus Jönsson (1961, traduzido para do alemão para o inglês em 1974) demonstra esta asserção com elétrons.

10 A grafia atualmente aceita como correta é "Autorrepetição". Entretanto, no simulador aparece "Autorepetição", pois a tradução foi realizada antes da reforma ortográfica.
} 
poderia ficar com um aspecto visual mais próximo do resultado com experimentos reais apresentados em TONOMURA et al., 1989.

Diante desta situação, na qual o fóton é lançado como partícula e atinge a tela como partícula (pontos na Figura 5b), mas se comporta como onda devido as formações de espaços com maior concentração de fótons, entre espaços com menor concentração, nos resta a questão: por qual fenda o fóton passou antes de chegar na tela? Para responder esta questão "colocamos" detectores nas fendas com o objetivo de observar por qual fenda o fóton atravessou. Feynman (FEYNMAN et al., 2008) sugere, para realizar a detecção de elétrons, conforme destacado no seguinte trecho:

Ao nosso aparato de elétrons vamos colocar uma fonte de luz forte atrás da parede entre os dois orifícios, [...] Sabemos que cargas elétricas espalham luz. Então quando um elétron passar, se ele passar, em seu caminho para o detector, ele espalhará a luz para os nossos olhos e, então, poderemos ver aonde os elétrons vão... Se um elétron passa pelo orifício 1, esperaríamos ver um flash da vizinhança de cima deste orifício.

O novo aparato proposto por Feynman aparece na Fig. 6 e é constituído por uma fonte (um filamento de tungstênio), uma parede com duas fendas, 1 e 2, com uma distância $a$ uma da outra, uma fonte de luz $L$ e dois detectores $D_{1}$ e $D_{2}$ apontados para as fendas. As fendas estão a uma distância $d$ do anteparo. Para medir onde o elétron chega, é utilizado um contador Geiger na parede.

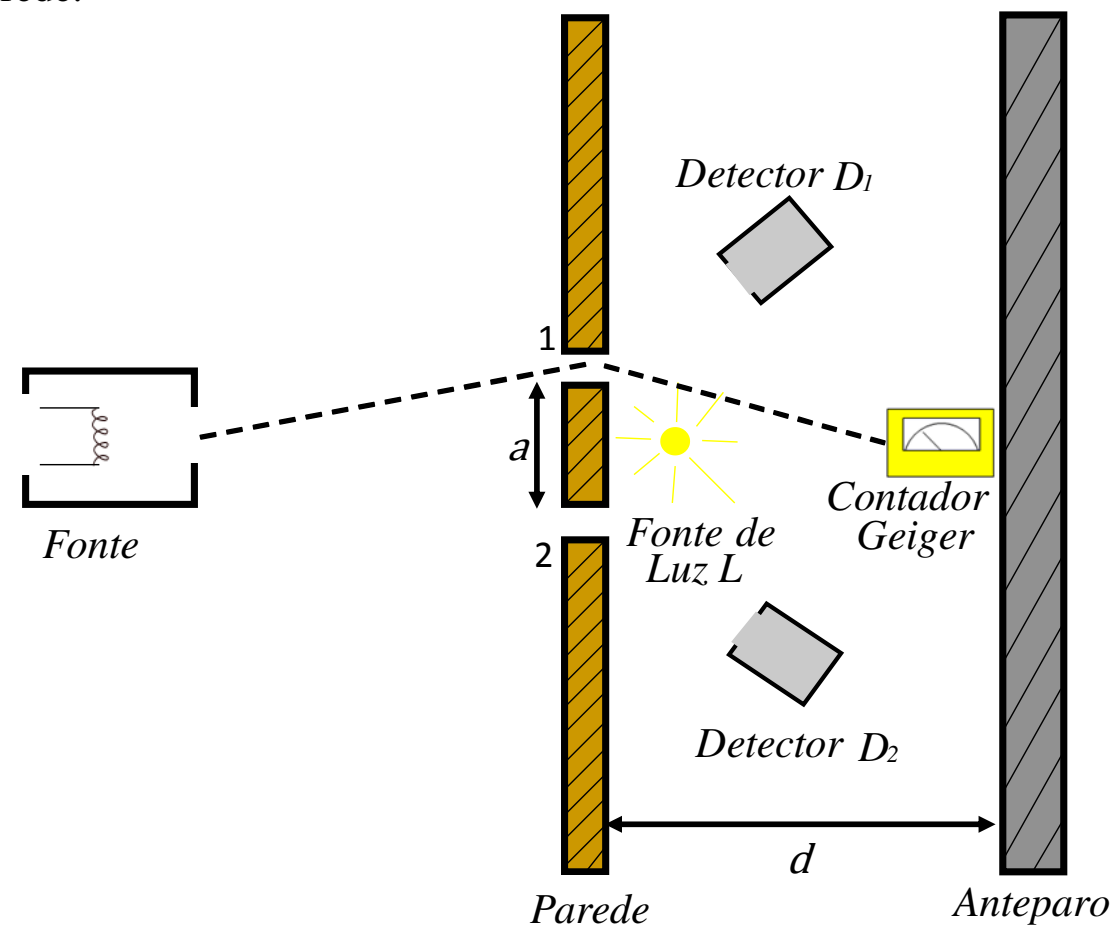

Fig. 6 - Aparato experimental da dupla fenda com detectores proposto por Feynman. 
Optamos em trabalhar com fótons. Mas, assim como Feynman, poderíamos ter trabalhado com elétrons e os resultados mostrados nesta seção seriam similares. Tanto os fótons, quanto os elétrons, são objetos quânticos. Os resultados experimentais com objetos quânticos, quando se usa o aparato experimental da dupla fenda, apresentam interferência (JÖNSSON 1974; ZEILINGER et al., 1988; CARNAL, MLYNEK 1991, SHIMIZU et al., 1992).

Trabalhando com o experimento virtual Interferência Quântica, não conseguiremos fazer a detecção da mesma forma como descreveu Feynman. Este fato não representa uma limitação, por não interferir no resultado final do experimento. Utilizando as mesmas condições, anteriormente, selecionamos a opção "dupla fenda" e "ligar" o laser. O resultado é idêntico ao encontrado na Fig. 5.

Para adicionar um detector em alguma das fendas selecionamos ou a opção "Detector na fenda esquerda" ou a opção "Detector na fenda direita". Aparece no simulador um retângulo azul na fenda em que se optou a detecção (direita ou esquerda), e o resultado fica uma faixa de luz contínua na tela como mostrado na Fig. 7a. Este resultado revela que ao tentar observar por qual fenda o fóton passou, o seu comportamento deixa de ser ondulatório e volta a ser corpuscular. Poderíamos ter selecionado a opção "Detector na fenda direita" ou até mesmo o detector em ambas as fendas. O resultado sempre é igual ao apresentado na Fig. 7a.

A Fig. $7 b$ mostra o mesmo resultado obtido na Fig. 7a, mas com a alteração para partículas únicas. A distribuição de partículas na tela de detecção é praticamente constante, revelando o comportamento corpuscular dos fótons, quando há detectores no aparato experimental da dupla fenda. Para realizar o experimento com detectores e partículas únicas utilizamos respectivamente as opções "Detectores" e, em seguida, selecionamos "Repetir Detecção". A opção "Auto-detecção"11 estará ativa quando selecionamos a opção "Detectores". Caso seja desativada a opção "Auto-detecção" os fótons voltarão a se comportar como ondas.

Podemos concluir com estes resultados no experimento virtual que, enquanto não tentamos observar por qual fenda o fóton passou, seu comportamento será ondulatório. Mas se tentarmos e, conseguirmos detectar por qual fenda o fóton passou, então seu comportamento será corpuscular.

Quando inserimos um detector como uma lâmpada, este enviará luz isotrópica na forma de fótons. Estes fótons colidirão com os objetos quânticos que passam pelas fendas. Estes objetos quânticos, no nosso caso, também são fótons, ou seja, ao inserir luz para observar por qual fenda o fóton passou, estaremos proporcionando inúmeras colisões, podendo ser consideradas clássicas, entre os fótons que saem da lâmpada e os fótons que passaram pela fenda, havendo transferência de energia e momento. Consequentemente, o padrão de interferência será destruído, e assim:

\footnotetext{
${ }^{11}$ A grafia atualmente aceita como correta é "Autodetecção". Entretanto, no simulador aparece "Auto-detecção", pois a tradução foi realizada antes da reforma ortográfica.
} 

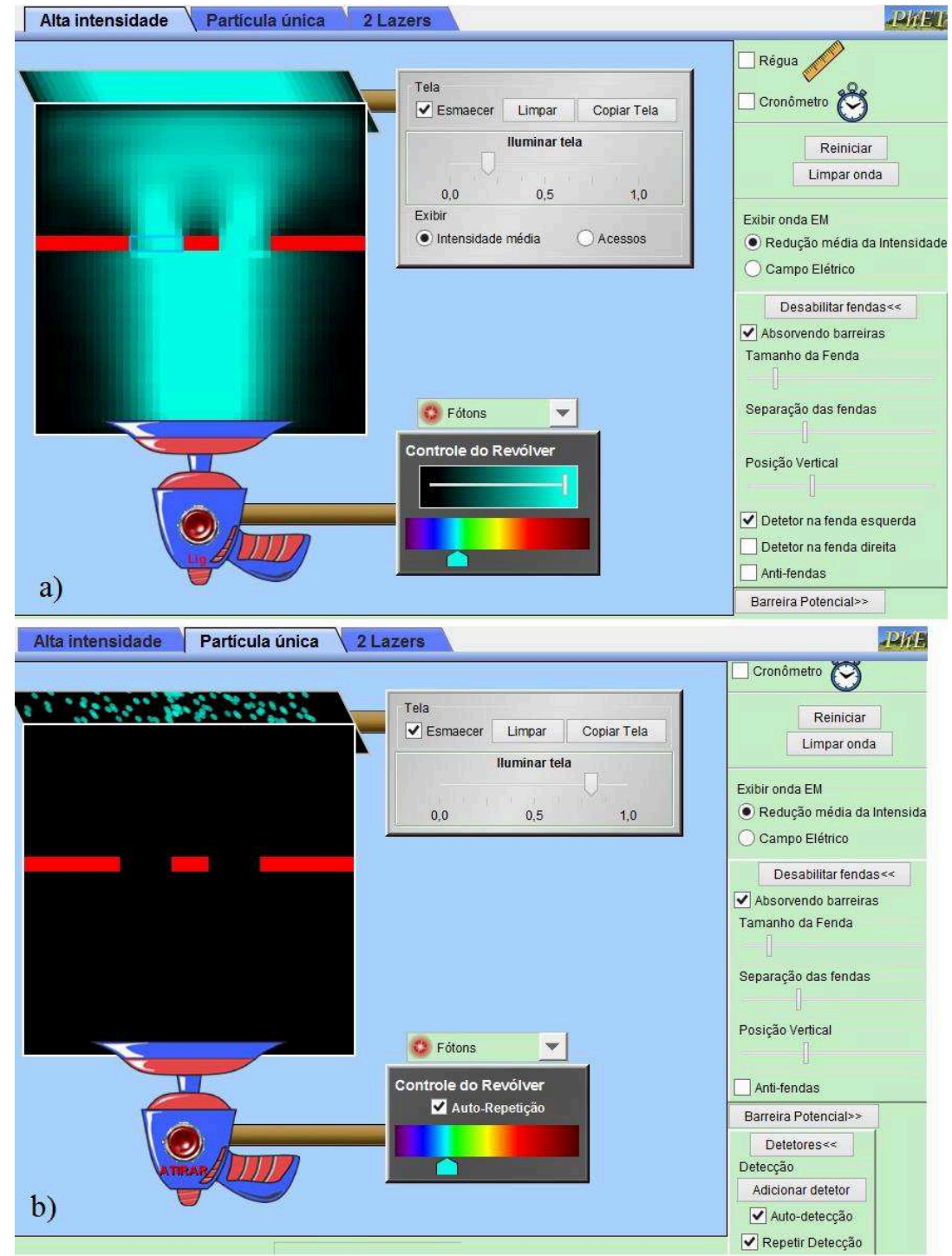

Fig. 7 - Experimento virtual Interferência Quântica. Destruição do padrão de interferência. a) "Alta intensidade". b) "Partícula única".

Quando observamos uma bola de futebol e jogamos luz sobre ela, isso não faz diferença: a bola continua do mesmo jeito. Mas quando jogamos luz forte sobre um elétron, ela esbarra nele. Em vez de fazer um movimento, ele faz outro [...] É impossível regular a luz de modo que sejamos capazes de saber por qual fenda ele [elétron ou fóton] passou; [...] É impossível projetar um aparelho para determinar por qual fenda os elétrons passaram sem perturbar esses elétrons de um modo que destruirá o padrão de interferência. [...] Eles sempre passam por uma ou por outra, quando você está olhando, [...] quando não estamos olhando, conduz a erros de previsão. [...]. Este caráter aleatório não decorre de ignorarmos os mecanismos ou as complicações internas; parece ser algo intrínseco (FEYNMAN, 2012, p. 145-53). 
Podemos tentar responder este problema fazendo uso do Princípio da Incerteza de Heisenberg. Considerando um aparato experimental que possua algum instrumento de medida que seja capaz de identificar por qual fenda o objeto quântico passou, então conheceremos com grande precisão a posição. Pelo princípio da Incerteza $\Delta p_{x} \Delta x>h$ isto significa alta imprecisão no momento, ou seja, o movimento do objeto quântico será alterado devido às interações entre fótons da fonte de luz e objeto quântico que atravessou a fenda.

Um exemplo da imprecisão que ocorre quando inserimos um detector no experimento da dupla fenda é apresentado em Gasiorowicz (1979). Imaginando que o detector da Fig. 6 tenha uma precisão de $\Delta y<a / 2$, ou seja, o detector é capaz de determinar por qual fenda o objeto quântico passou, a indeterminação na posição do objeto quântico passa a ser da ordem $2 \lambda d / a$, onde $\lambda$ é o comprimento de onda do objeto quântico. Como a distância entre a franja observada $m$ e a franja central pode ser escrita (CALÇADA; SAMPAIO, 2001) como $m=N \lambda d / 2 a$, onde $N$ é o número da ordem da franja, $N$ precisa ser no mínimo igual a 4 para corresponder a imprecisão de $2 \lambda d / a$, isto é, o monitor apagará a figura de interferência.

Para minimizar a transferência de momento podemos recorrer a expressão devida a De Broglie, $\lambda=h / p$, e utilizar a estratégia proposta por Feynman de aumentar o comprimento de onda já que o mesmo é inversamente proporcional ao momento. Entretanto, ao realizar esta mudança, deixamos de ser capazes de distinguir dois pontos (FEYNMAN et al., 2008). Existem propostas de medição por qual fenda o objeto quântico passou sem provocar distúrbios utilizando experimentos mentais (SCULLY, 1991) e técnicas experimentais (WALBORN, 2002). Todavia, se for observada a trajetória do objeto quântico o padrão de interferência desaparece.

Nas duas próximas seções, mostraremos como duas distintas escolas de pensamento interpretam este estranho fenômeno. Contudo, não há uma solução razoável para este enigma. Não conseguimos explicar, dialogicamente, por qual fenda o fóton passou, mas podemos explicar matematicamente os resultados do experimento da dupla fenda, utilizando a notação de Dirac. Desta forma, nas próximas seções realizaremos uma revisão bibliográfica, com nossas adaptações, do livro Lições de Física de Feynman (FEYNMAN et al., 2008).

\section{O Formalismo Matemático da Mecânica Quântica ${ }^{12}$}

Para elucidar a simplicidade do formalismo matemático da mecânica quântica, quando utilizamos as regras propostas por Feynman e colaboradores (FEYNMAN et al., 2008) destacamos o seguinte trecho:

Chegamos à conclusão de que as chamadas "partes avançadas" da mecânica quântica são de fato muito simples. A matemática necessária é particularmente simples,

\footnotetext{
12 Para redigir esta seção, consultamos as seguintes referências: Dirac (1958); Dicke e Wittke (1961); CohenTannoudji et al. (1977); Gasiorowicz (1979); Merzbacher (1997); Nussenzveig (1998); Mahon (2011), além das demais referências citadas no decorrer do artigo.
} 
envolvendo operações algébricas simples, sem equações diferenciais ou no máximo, as mais simples delas. O único problema é que temos que pular a lacuna de não sermos mais capazes de descrever o comportamento em detalhe das partículas no espaço.

O assunto avançado ao qual Feynman se refere é o spin do elétron que é tratado nos capítulos seguintes de seu livro de Lições de Física Feynman (FEYNMAN et al., 2008). As equações diferenciais citadas são relativas a equação de onda de Erwin Schrödinger (18871961) que não serão discutidas neste trabalho. Os autores ainda relatam que "Na verdade, uma das razões de tentarmos ser cuidadosamente precisos nos capítulos seguintes é que podemos mostrar uma das coisas mais bonitas da mecânica quântica - o tanto que se pode deduzir de tão pouco".

Devemos observar que no ensino de física moderna no ciclo médio, pouco é feito sobre o desenvolvimento matemático da mecânica quântica. No decorrer desta seção mostraremos como a notação de Dirac pode ser utilizada, desde o nível do ensino médio, realizando um tratamento com brackets e vetores de estado no experimento da dupla fenda. Para tanto, desenvolvemos a seguir uma revisão literária do livro de Lições de Física de Feynman (FEYNMAN et al., 2008) com algumas alterações para adaptar a noção de Dirac e introduzirmos vetores de estado no nível médio.

Na seção II foi possível mostrar que objetos quânticos sofrem interferência no experimento da dupla fenda, quando não há nenhum detector próximo as fendas. Devido a este fato, e à interferência se constituir num fenômeno típico de ondas, podemos realizar comparações entre objetos quânticos e ondas. Antes de iniciarmos esta abordagem, façamos duas considerações:

Primeiro, a expressão para interferência de ondas (expressão 3) foi analisada em aspectos de suas intensidades na parte I deste trabalho. A intensidade é proporcional à amplitude (altura) ao quadrado (expressão 4) da onda que chega em $x$. Procedemos da mesma forma para entes quânticos trocando intensidade por probabilidade, devido ao fato de trabalharmos com partículas, logo mediremos probabilidade de chegada, ao invés de intensidades.

O segundo ponto a destacar é o fato da necessidade de a amplitude de probabilidade ser um número complexo. Isto se deve à representação realizada na equação (2) para a equação de onda. Sendo assim, esta característica das amplitudes de probabilidade é evidenciada na comparação com as ondas. Entretanto, deve-se destacar que o fato da amplitude de onda ser complexa, não interfere no resultado da medida de probabilidade, que sempre corresponde aos resultados expressos por números reais ${ }^{13}$.

\footnotetext{
${ }^{13}$ Seja um número complexo $z$ representado por: $z=a+i \cdot b$ onde $a$ é a parte real e $i \cdot b$ é a parte imaginária e $i$ é a unidade imaginária $\left(i^{2}=-1\right)$. O complexo conjugado de $z$ é $z^{*}$

O produto de dois números complexos é:

$$
z^{*}=a-i \cdot b
$$
}




\section{V.1 Notação de Dirac}

Inicialmente, mostraremos os princípios gerais (ou regras gerais) para utilizar a notação específica da mecânica quântica. Esta introdução é um método criado por Feynman e colaboradores com a finalidade de destacar a facilidade do uso de vetores de estado através de brackets (FEYNMAN et al., 2008).

Nosso primeiro princípio geral da mecânica quântica é que a probabilidade de que uma partícula chegará em $x$, quando sai da fonte s, pode ser representada quantitativamente pelo quadrado de um número complexo chamado de amplitude de probabilidade - nesse caso, a “amplitude que uma partícula saindo de s chega em x”.

A representação da amplitude de probabilidade é:

$$
\begin{aligned}
& \langle\text { Partícula chega em } x| \text { partícula deixa s }\rangle \\
& \left\{\begin{array}{l}
\langle\ldots\rangle \text { é um sinal equivalente a a amplitude de que; } \\
|\ldots\rangle \text { condição inicial; } \\
\langle\ldots| \text { condição final. }
\end{array}\right.
\end{aligned}
$$

Uma forma de resumir a notação na expressão (6), é escrever abreviadamente $\langle x \mid s\rangle$ e, enfim, representar a probabilidade descrita no primeiro princípio geral:

$$
P(x)=|\langle x \mid s\rangle|^{2}
$$

Tal amplitude é apenas um número, um número complexo. O segundo princípio é (FEYNMAN et al., 2008): "segundo princípio geral da mecânica quântica, quando uma partícula pode alcançar um certo estado por duas rotas possíveis, a amplitude total para o processo é a soma das amplitudes para cada rota separadamente”. Com a nova notação temos:

$$
\langle x \mid s\rangle_{\text {ambos orifícios abertos }}=\langle x \mid s\rangle_{\text {através de } 1}+\langle x \mid s\rangle_{\text {através de } 2}
$$

Supõem-se que os orifícios sejam suficientemente pequenos, de tal forma que, quando dissermos que o objeto quântico passou através do orifício, não precisamos nos preocupar em qual parte do orifício o fóton passou. O terceiro princípio é destacado por Feynman (FEYNMAN et al., 2008) como:

Agora podemos escrever com mais detalhes o que podemos dizer sobre a amplitude para o processo no qual o elétron chega em x pelo orifício 1. Podemos fazer isto usando o nosso terceiro princípio geral: quando uma partícula vai por alguma rota

$$
z^{*} z=(a-i \cdot b)(a+i \cdot b)=a^{2}+i \cdot a b-i \cdot a b+b^{2}=a^{2}+b^{2}
$$

Este resultado é um número real. Sendo assim, o quadrado de números complexos corresponde a um resultado real. Mesmo assim, não se deve atribuir nenhuma realidade a onda da amplitude de probabilidade da equação de Schrödinger (que não será discutida neste trabalho). 
particular a amplitude para aquela rota pode ser escrita como o produto da amplitude para ir parte do caminho com a amplitude de ir o restante.

Assim a amplitude para ir de $s$ a $x$ pelo orifício 1, fenda $F_{1}$, é igual a amplitude de ir se $s$ até 1, multiplicado pela amplitude de ir de 1 a $x$. O mesmo vale para a ir pelo orifício 2, $F_{2}$.

$$
\left\{\begin{array}{l}
\langle x \mid s\rangle_{\text {via } 1}=\left\langle x \mid F_{1}\right\rangle\left\langle F_{1} \mid s\right\rangle \\
\langle x \mid s\rangle_{\text {via } 2}=\left\langle x \mid F_{2}\right\rangle\left\langle F_{2} \mid s\right\rangle
\end{array}\right.
$$

A expressão deve ser lida da direita para a esquerda: o objeto quântico vai de $s$ a 1, e então, de 1 a $x$. Portanto, podemos escrever que:

$$
\langle x \mid s\rangle_{\text {ambos }}=\left\langle x \mid F_{1}\right\rangle\left\langle F_{1} \mid s\right\rangle+\left\langle x \mid F_{2}\right\rangle\left\langle F_{2} \mid s\right\rangle
$$

Feynman et al. (2008) ainda destacam que: "Entretanto, deve ser enfatizado que a função de onda que satisfaz a equação, não é uma onda real no espaço; não podemos atribuir nenhuma realidade a essa onda como fazemos com a onda sonora".

Não é uma boa ideia pensar em termos de ondas de partícula. Quando trabalhamos com duas (ou mais) partículas precisamos do seguinte princípio adicional: [...] desde que duas partículas não interajam, a amplitude que uma partícula faça uma coisa e, a outra partícula faça outra, é o produto das duas amplitudes que as duas partículas fariam as duas coisas, separadamente (FEYNMAN et al., 2008).

É possível fazer previsões do que ocorre após a fenda, se for dado as amplitudes de ter chegado aos orifícios (FEYNMAN et al., 2008), isto é, se conhecermos os números $\left\langle F_{1} \mid s\right\rangle$ e $\left\langle F_{2} \mid s\right\rangle$ e, usarmos a relação na nota de rodapé 13.

\section{V.2 O padrão de interferência de duas fendas}

A situação analisada nesta seção é de profunda importância. Feynman (FEYNMAN et al., 2008) explica, através de vetores de estado a estranheza no experimento da dupla fenda, quando se coloca um detector e uma fonte de luz, em busca de descobrir por qual caminho o fóton rumou para chegar no anteparo final. Para sintetizar a notação definimos $\psi_{1}$, como a amplitude para o objeto quântico chegar em $x$ através do orifício 1, ou seja:

$$
\psi_{1}=\left\langle x \mid F_{1}\right\rangle\left\langle F_{1} \mid s\right\rangle
$$

e $\psi_{2}$ a amplitude para o elétron chegar no detector através do orifício 2, isto é:

$$
\psi_{2}=\left\langle x \mid F_{2}\right\rangle\left\langle F_{2} \mid s\right\rangle
$$

estas são as amplitudes para o objeto quântico ir pelos dois orifícios e chegar em $x$, se não houver fótons interagindo com ele. 
A amplitude para o processo no qual um objeto quântico começa em $s$ e um fóton é liberado pela fonte de luz $L$, finalizando com o objeto quântico em $x$ e um fóton visto atrás da fenda, supondo que observamos o fóton atrás da fenda 1 por meio de um detector $D_{1}$, requer que adotemos uma amplitude para um fóton chegar em $D_{l}$ e um objeto quântico chegar em $x$, que será simbolizada por " $a$ " e, também uma amplitude para um fóton chegar em $D_{2}$ e um objeto quântico chegar em $x$, que será simbolizada por " $b$ ".

Para tanto, adotamos a seguinte nomenclatura que aparece nos quadros 1 e 2 .

Quadro 1: Vetores de estado das amplitudes de probabilidade dos objetos quântico que passam pela fenda $\mathrm{F}_{1}$ e espalha um fóton no detector $\mathrm{D}_{1}$.

\begin{tabular}{|c|l|}
\hline Amplitude de Probabilidade & Descrição da Amplitude \\
\hline$\left\langle F_{1} \mid s\right\rangle$ & objeto quântico vai da fonte $s$ para o orifício 1 \\
\hline$a$ & $\begin{array}{l}\text { objeto quântico no orifício } 1 \text { espalha um fóton no detec- } \\
\text { tor } D_{1}\end{array}$ \\
\hline$\left\langle x \mid F_{1}\right\rangle$ & objeto quântico vai da fenda 1 para o anteparo $x$ \\
\hline
\end{tabular}

Quadro 2: Vetores de estado das amplitudes de probabilidade dos objetos quânticos que passam pela fenda $\mathrm{F}_{2}$ e espalha um fóton no detector $\mathrm{D}_{1}$.

\begin{tabular}{|c|l|}
\hline Amplitude de Probabilidade & Descrição da Amplitude \\
\hline$\left\langle F_{2} \mid s\right\rangle$ & objeto quântico vai da fonte $s$ para o orifício 2 \\
\hline$b$ & $\begin{array}{l}\text { objeto quântico no orifício } 2 \text { espalha um fóton no detec- } \\
\text { tor } D_{1}\end{array}$ \\
\hline$\left\langle x \mid F_{2}\right\rangle$ & objeto quântico vai da fenda 2 para o anteparo $x$ \\
\hline
\end{tabular}

Podemos escrever, desta forma, as amplitudes para o objeto quântico passar por uma dada fenda e espalhar um fóton proveniente da lâmpada no detector. Para tanto:

Quadro 3: Vetores de estado das amplitudes de probabilidade dos objetos quânticos que passam pelas fendas $F_{1}$ e $F_{2}$ e espalham fótons no detector $D_{1}$.

\begin{tabular}{|c|l|}
\hline Amplitude de Probabilidade & Descrição da Amplitude \\
\hline$\left\langle x \mid F_{1}\right\rangle a\left\langle F_{1} \mid s\right\rangle=a \psi_{1}$ & $\begin{array}{l}\text { amplitude para que o objeto quântico vai de } s \\
\text { para } x \text { via fenda 1 e espalha um fóton em } D_{1}\end{array}$ \\
\hline$\left\langle x \mid F_{2}\right\rangle b\left\langle F_{2} \mid s\right\rangle=b \psi_{2}$ & $\begin{array}{l}\text { amplitude para que o objeto quântico vai de } s \\
\text { para } x \text { via fenda 2 e espalha um fóton em } D_{1}\end{array}$ \\
\hline
\end{tabular}


Usando o segundo princípio geral: "quando uma partícula pode alcançar um certo estado por duas rotas possíveis, a amplitude total para o processo é a soma das amplitudes para cada rota separadamente" (FEYNMAN et al., 2008). Podemos escrever que a amplitude de probabilidade para um objeto quântico que sai de $s$ e chega em $x$, por alguma das fendas e, espalha fótons no detector $D_{l}$, é a soma dos dois termos (quadro 3), que representa cada possível trajetória do elétron:

$$
\left(\begin{array}{c|c}
\text { objeto quântico em x } & \text { objeto quântico em } s \\
\text { fóton em } D_{1} & \text { fóton em } L
\end{array}\right\rangle=a \psi_{1}+b \psi_{2}
$$

Nas Fig. 8a e 8b, mostramos as amplitudes de probabilidade do quadro 3. Mostramos estas figuras para, por meio de simetria, escrever a amplitude de probabilidade para um objeto quântico que sai de $s$ e chega em $x$, por alguma das fendas e, espalham fótons no detector $D_{2}$. Podemos observar, na Fig. 8a, que o objeto quântico no orifício 1 espalha um fóton no detector $D_{1}$ e amplitude de probabilidade para este fenômeno é $a$ (tabela 1). Da mesma forma, na Fig. 8 b, o objeto quântico no orifício 2 espalha um fóton no detector $D_{1}$ e amplitude de probabilidade para este fenômeno é $b$ (tabela 2).

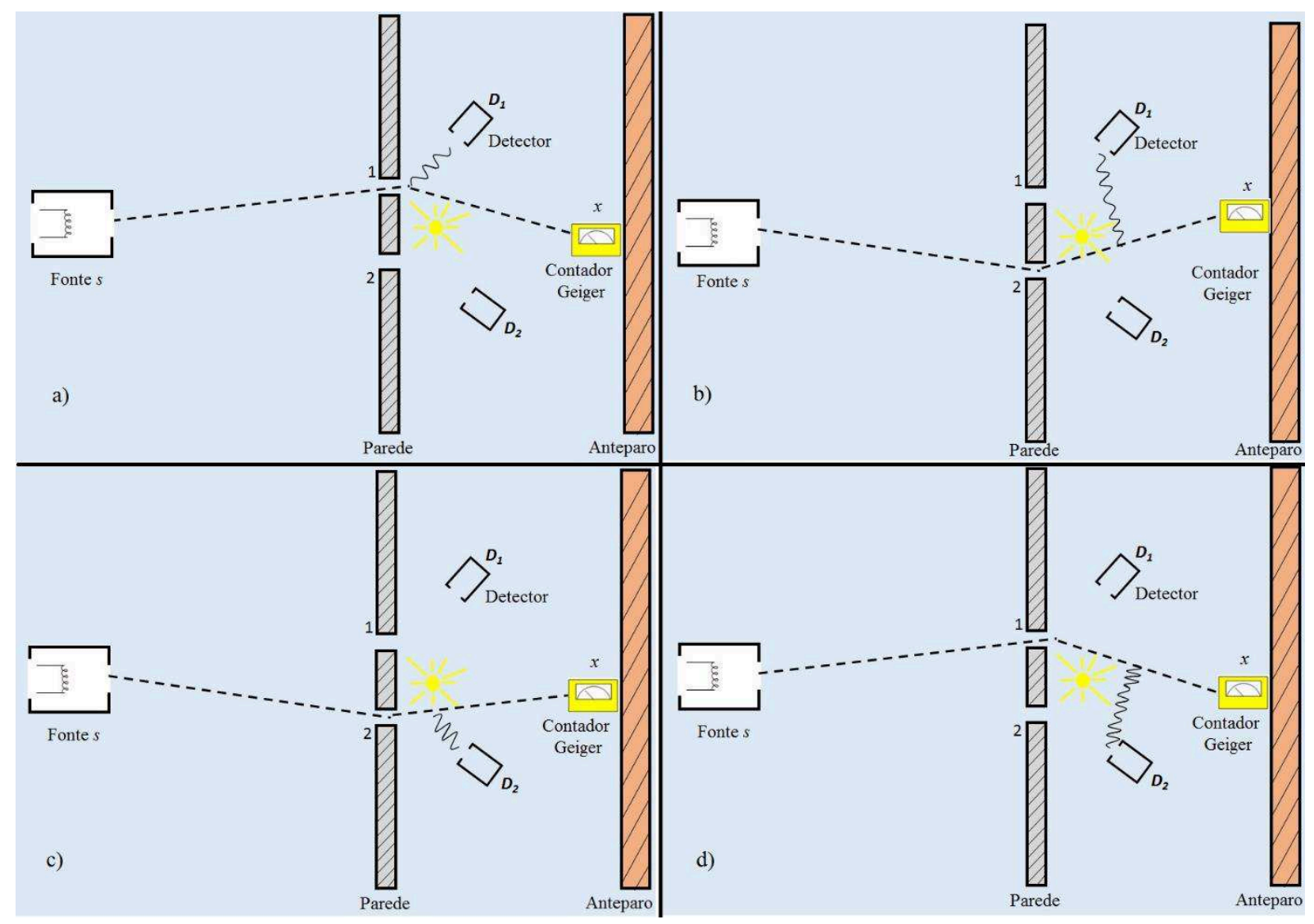

Fig. 8 - Experimento virtual Interferência Quântica. Destruição do padrão de interferência. a) "Alta intensidade”. b) "Partícula única". 
Observando as Fig. 8c e 8b, na Fig. 8a o objeto quântico espalha um fóton similarmente ao espalhamento mostrado na Fig. 8c. Determinamos no fenômeno mostrado na Fig. $8 \mathrm{a}$, que a amplitude de probabilidade deveria ser igual a " $a$ ". Por simetria, podemos determinar que o espalhamento mostrado na Fig. $8 \mathrm{c}$ também é igual a " $a$ ".

Da mesma forma, na Fig. 8b o objeto quântico espalha um fóton similarmente ao espalhamento mostrado na Fig. 8d. Determinamos no fenômeno mostrado na Fig. 8b que a amplitude de probabilidade deveria ser igual a " $b$ ". Por simetria podemos determinar que o espalhamento mostrado na Fig. 8d também é igual a " $b$ ". Resumindo:

Quadro 4 - Vetores de estado das amplitudes de probabilidade dos objetos quântico que passam pelas fendas $\mathrm{F}_{1}$ e $\mathrm{F}_{2}$ e espalham fótons no detector $\mathrm{D}_{2}$.

\begin{tabular}{|c|l|}
\hline Amplitude de Probabilidade & Descrição da Amplitude \\
\hline$\left\langle x \mid F_{2}\right\rangle a\left\langle F_{2} \mid s\right\rangle=a \psi_{2}$ & $\begin{array}{l}\text { amplitude para que o objeto quântico vai de } s \\
\text { para } x \text { via fenda 2 e espalha um fóton em } D_{2}\end{array}$ \\
\hline$\left\langle x \mid F_{1}\right\rangle b\left\langle F_{1} \mid s\right\rangle=b \psi_{1}$ & $\begin{array}{l}\text { amplitude para que o objeto quântico vai de } s \\
\text { para } x \text { via fenda 1 e espalha um fóton em } D_{2}\end{array}$ \\
\hline
\end{tabular}

Podemos escrever que a amplitude de probabilidade para um objeto quântico que sai de $s$ e chega em $x$, por alguma das fendas e, espalha fótons no detector $D_{2}$, é a soma dos dois termos (quadro 4), que representa cada possível trajetória do objeto quântico:

$$
\left\langle\begin{array}{c}
\text { objeto quântico em } x \\
\text { fóton em } D_{2}
\end{array} \quad \begin{array}{c}
\text { objeto quântico em } s \\
\text { fóton em } L
\end{array}\right\rangle=a \psi_{2}+b \psi_{1}
$$

Com estes resultados podemos determinar, por exemplo, a probabilidade de obter contagem em $D_{l}$ e um objeto quântico em $x$. Usando o primeiro princípio geral no qual devemos tomar o quadrado da amplitude de probabilidade estabelecida na expressão (9):

$$
P\left(D_{1}, x ; s\right)=\left|a \psi_{1}+b \psi_{2}\right|^{2}
$$

Analisando a expressão (11) não é possível inferir por qual fenda o objeto quântico atravessou para chegar em $x$. Quando não conseguimos dizer qual a trajetória do objeto quântico, observaremos a interferência. Entretanto, se tamparmos a fenda 2, consequentemente o objeto quântico apenas poderá chegar em $x$ através do orifício 1. Desta forma, podemos conhecer a trajetória do objeto quântico. Tampar a fenda 2 significa fazer na expressão (11) $\psi_{2}=0$, isto é:

$$
P\left(D_{1}, x ; s\right)=\left|a \psi_{1}+b \cdot 0\right|^{2}=\left|a \psi_{1}\right|^{2}=|a|^{2}\left|\psi_{1}\right|^{2}
$$

O gráfico da expressão (12) é uma curva parabólica, isto é, o objeto quântico se comporta como partícula quando se cobre uma das fendas (Fig. 3a).

Para determinar qual a probabilidade de encontramos um objeto quântico em $x$ e um fóton em $D_{1}$ ou $D_{2}$ é necessário observar que: (i) nunca se deve somar amplitudes de estados 
finais diferentes e distintos e; (ii) apenas se soma amplitudes para diferentes alternativas indistinguíveis dentro do experimento, antes que termine o processo (FEYNMAN et al., 2008). Assim:

$$
\begin{aligned}
& P\left(D_{2}, D_{1}, x ; s\right) \\
& =\left.\left|\begin{array}{c|c}
\text { objeto quântico } x & \text { objeto quântico em s } \\
\text { fóton em } D_{1} & \text { fóton em } L
\end{array}\right|\right|^{2} \\
& +\left.\left|\begin{array}{c}
\text { objeto quântico em } x \\
\text { fóton em } D_{2}
\end{array} \begin{array}{c}
\text { objeto quântico em } s \\
\text { fóton em } L
\end{array}\right|\right|^{2} \\
& =\left|a \psi_{1}+b \psi_{2}\right|^{2}+\left|a \psi_{2}+b \psi_{1}\right|^{2}
\end{aligned}
$$

\section{Considerações finais}

Conseguimos explicar, matematicamente, o experimento da dupla fenda utilizando a notação de Dirac de brackets para representar os vetores de estado. Entretanto, não resolvemos o seguinte paradigma: se atribuímos ao fóton a condição de estado como partícula, não conseguimos explicar o experimento da dupla fenda. Isto se deve ao fato de que para ocorrer interferência, no experimento da dupla fenda com ondas de água, é necessário que os trens de ondas, ao passarem pelas fendas, difratem, conforme mostrado na parte I deste trabalho.

O equivalente para partículas é um corpúsculo que passe ao mesmo tempo pelas duas fendas. Mas, isto, parece um absurdo. O fóton chega ao anteparo inteiro, logo, ele não se divide durante seu caminho. Quando tentamos observar por qual fenda o fóton passou, os fótons não interferem e se comportam como partículas. Este embaraçoso problema gera muitas discussões. Afinal, o que acontece com os fótons depois de serem disparados?

Tantas são as propostas para explicar o que acontece com os objetos quânticos no experimento da dupla fenda, que a consequência desta discussão foi o surgimento de diferentes interpretações da mecânica quântica. Destacaremos duas: interpretação dualista realista objetiva e interpretação de Copenhagen ${ }^{14}$.

Uma excelente apresentação do Realismo Dualista Objetivo, escola de pensamento devido a Einstein e de Broglie, aparece no artigo de Bastos Filho e Siqueira (BASTOS FILHO; SIQUEIRA; 1993). Tal trabalho realiza uma análise por meio de lógica distributiva com o objetivo de mostrar que o experimento da dupla fenda não possui incognoscibilidade.

Inicialmente, Bastos Filho e Siqueira (1993) sugere que objetos quânticos contêm, simultaneamente, características corpusculares e ondulatórias, ou seja, a partícula fóton possui uma onda associada. Desta forma, uma partícula que passa pela fenda 1 da Fig. 6 possui uma onda associada que passa pelas fendas 1 e 2 . 14 Existem outras interpretações como: teoria de variáveis ocultas, interpretação dos muitos mundos e posição
agnóstica. Está última acredita não ser necessário responder questões como localidade. 
No aparato experimental da dupla fenda teremos uma partícula que passa ou pela fenda 1 ou pela fenda 2, da Fig. 6, mas sempre haverá uma onda que passa pelas duas fendas, então ocorrerá interferência na sua onda associada. Quando tentamos observar por qual fenda o fóton passou, colocamos os detectores $D_{1}$ e $D_{2}$ apontados respectivamente para as fendas $1 \mathrm{e}$ 2. Uma partícula que passa pela fenda 1 pode ter sua onda associada absorvida ou por $D_{1}$ ou por $D_{2}$. O mesmo ocorre com uma partícula que passa pela fenda 2. Devido ao fato do detector absorver a onda associada ao fóton, o efeito de interferência, quando se coloca detectores, é destruído.

Os adeptos da escola de Copenhagen, devido a Niels Bohr (1885-1962) e Werner Heisenberg (1901-1976), aderem à exclusão mútua que aparece no princípio da complementariedade (PESSOA JR., 2003):

Um sistema quântico ou exibe aspectos corpusculares (seguindo trajetórias bem definidas), ou aspectos ondulatórios (como a formação de um padrão de interferência), dependendo do arranjo experimental, mas nunca ambos ao mesmo tempo. Essas não são as palavras de Bohr, mas exprimem a sua noção de que onda e partícula são aspectos mutuamente excludentes, mas complementares, da natureza.

Em seu livro de Conceitos de Física Quântica, O. Pessoa Jr (2003) ainda destaca que Bohr, diante do desafio do paradoxo EPR (Einstein, Podolsky e Rosen) é levado a refinar sua explicação da complementariedade de arranjos experimentais:

A novidade foi a êfase que Bohr passou a dar para o "todo" do arranjo experimental, ao se definir o "fenômeno" quântico: "A lição essencial da análise de medições na teoria quântica é pois a ênfase na necessidade, para dar conta do fenômeno, de levar em considerações o arranjo experimental como um todo, em completa conformidade com o fato de que toda interpretação não ambígua do formalismo quântico envolve a fixação de condições externas".

Caso o aparato experimental seja construído a dupla fenda utilizando ondas ou objetos quânticos, este arranjo é do tipo que exibe propriedades ondulatórias dos objetos quânticos. Utilizando ondas ou objetos quânticos ocorrerá difração nas fendas e as ondas difratadas sofreram superposições construtivas e destrutivas, ou seja, aparecerá um padrão de interferência típico de ondas.

Nos casos em que temos a fenda simples ou, são colocados detectores próximos aos orifícios no aparto experimental da dupla fenda, estes detectores poderão mostrar por qual fenda o objeto quântico atravessou. "Um fenômeno é corpuscular quando podemos inferir, após completada a medição, qual a trajetória do quantum detectado" (PESSOA JR., 2003).

Enfim, as duas interpretações, discutem os resultados do experimento da dupla fenda com objetos quânticos. Fica ao gosto do leitor qual escolher. Concluímos este trabalho mos- 
trando da forma mais elementar possível (a nosso ver) como introduzir mecânica quântica e seu formalismo matemático, seja numa disciplina de graduação, seja no ensino médio.

\section{Agradecimentos}

Os autores agradecem a Sociedade Brasileira de Física - SBF e a Coordenação de Aperfeiçoamento de Pessoal de Nível Superior - CAPES pela bolsa de Mestrado e por subsidiar o Mestrado Nacional Profissional em Ensino de Física - MNPEF. Agradecemos aos avaliadores deste trabalho pelos excelentes apontamentos e sugestões.

\section{Referências}

BASTOS FILHO, J. B.; SIQUEIRA, A. F. O experimento da dupla fenda como exemplo de incognoscibilidade? Revista Brasileira de Ensino de Física, v.15, n. 1 a 4, p. 153, 1993.

BOHR, N. Física atômica e conhecimento humano. Contraponto editora, 1996. 132p.

CALÇADA, C. S.; SAMPAIO, J. L. Física Clássica: Óptica e Ondas. 2. ed. São Paulo: Atual, 2001.

CARNAL, O.; MLYNEK, J. Young's Double-Slit Experiment with Atoms: A Simple Atom Interferometer. Physical Review Letters. v. 66, n. 21, p. 2689-2692, 1991.

COHEN-TANNOUDJ, C.; DIU, B.; LALOË, F. Quantum Mechanics. v. I. New York: John Wiley \& Sons, 1977.

DIRAC, P. A. M. The Principles of Quantum Mechanics. New York: Oxford Science Publications, 1958.

DICKE, R. H.; WITTKE, J. P. Introduction to Quantum Mechanics. Massachusetts: Addison-Wesley Company Inc, 1961.

EINSTEIN, A. Sobre um ponto de vista heurístico a respeito da produção e transformação da luz. In: STACHEL, J. (org.). $\mathrm{O}$ ano miraculoso de Einstein: cinco artigos que mudaram a face da Física. Tradução: Alexandre Carlos Tort. 2. ed. Rio de Janeiro: Editora da UFRJ, 2005. p. 201-222.

FERREIRA, D. C.; DE SOUZA FILHO, M. P. O experimento virtual da dupla fenda ao nível de ensino médio (Parte I): uma análise clássica do comportamento corpuscular e ondulatório e o desenvolvimento de um software computacional. Caderno Brasileiro de Ensino de Física, Florianópolis, v. 33, n. 2, p. 697-716, set. 2016.

FEYNMAN, R. P.; LEIGHTON, R. B.; SANDS, M. Lições de Física de Feynman. Mecânica Quântica. v. 3. Porto Alegre: Bookman, 2008.

FEYNMAN, R. P. Sobre as leis da Física. Rio de Janeiro: Contraponto Editora, 2012, 180p. 
GALVEZ, E. J.; HOLBROW, C. H.; PYSHER, M. J.; MARTIN, J. W.; COUTERMANCHE, N.; HEILIG, L.; SPENCER, J. Interference with correlated photons: Five quantum mechanics experiments for undergraduates. American Journal of Physics, v. 73, n. 127, 2005.

GASIOROWICZ, S. Física Quântica. Rio de Janeiro: Guanabara Dois, 1979.

HEISENBERG, W. A parte e o todo. Rio de Janeiro: Contraponto Editora, 1996. 288p.

JÖNSSON, C. Electron diffraction at multiple slits. Tradução: Dietrich Brandt e Stanley Hirschi. American Journal of Physics, v. 42, n. 1, p. 4-11, 1974. Título original: Elektroneninterferenzen an mehreren ktinstlich hergestellten Feinspalten.

MAHON, J. R. P. Mecânica Quântica: desenvolvimento contemporâneo com aplicações, Rio de Janeiro: LTC, 2011.

MAXWELL, J. C. A Dinamical Theory of the Electromagnetic Field. Engene: Wipf and Stock Publishers, 1982.

MERZBACHER, E. Quantum Mechanics. New York: John Wiley \& Sons, 1997.

MOURA, B. A. Newton versus Huygens: como (não) ocorreu a disputa entre suas teorias. Caderno Brasileiro de Ensino de Física, Florianópolis, v. 33, n. 1, p. 111-141, abr. 2016.

NEWTON, I. Óptica. Tradução: André Koch Torres de Assis. 1. ed. 1ª reimpr. São Paulo: editora da USP, 2002.

NUSSENZVEIG, H. M. Física Básica. Ótica, Relatividade e Física Quântica. v. 4. São Paulo: Blucher, 1998.

OSTERMANN, F.; RICCI, T. S. F. Conceitos de Física quântica na formação de professores: relato de uma experiência didática centrada no uso de experimentos virtuais. Caderno Brasileiro de Ensino de Física, Florianópolis, v. 22, n. 1, p. 9-35, jan. 2005.

PESSOA Jr. O. Conceitos de Física Quântica. v. 1e 2. São Paulo: Livraria da Física, 2003.

PLANCK, M. Autobiografia Científica e outros ensaios. Rio de Janeiro: Contraponto Editora, 2012. 236p.

ROSA, P. S. Louis de Broglie e as ondas de matéria. 2004. Dissertação (Mestrado em Física) - Instituto de Física “Gleb Wataghin, Universidade de Campinas, Campinas.

SAYER, R.; MARIES, A.; CHANDRALEKHA, S. Quantum interactive learning tutorial on the double-slit experiment to improve student understanding of quantum mechanics. Physical Review: Physics Education Research. v. 13, n. 010123, 2017.

SILVA, F. W. O. A evolução da teoria ondulatória e os livros didáticos. Revista Brasileira de Ensino de Física, v. 29, n. 1, p. 149-59, 2007. 
SHIMIZU, F.; SHIMIZU, K.; TAKUMA, H. Double-slit interference with ultracold metastable neon atoms. Physical Review A, v. 46, n. 1, p. R17-R20, 1992.

SCULLY, M. O.; ENGLERT, B. G.; WALTHER, H. Quantum optical test of complementarity. Nature, v. 351, p. 111-116, 1991.

TONOMURA, A.; ENDO, J.; MATSUDA, T.; KAWASAKI, T.; ESAWA, H. Demonstration of singleelectron buildup of an interference pattern. American Journal of Physics, v. 57, n. 2, p. 117-120, 1989.

WALBORN, S. P.; CUNHA, M. O. T.; PÁDUA, S.; MONKEN, C. H. Double-slit quantum eraser. Physical Review A, v. 65, n. 3, p. 033818.1-033818.6, 2002.

ZEILINGER, A; GÄHLER, R.; SHULL, C. G.; TREIMER, W.; MAMPE, W. Single- and double-slit diffraction of neutrons. Reviews of Modern Physics, v. 60, n. 4, p. 1067-1073, 1988. 